\section{SOME PHYSIOLOGICAL EFFECTS OF HIGH-FREQUENCY CURRENTS IN DISEASE. 1}

By SAMUEL SLOAN, M.D. GlasG., F.F.P.S. GlasG.,

GONSULTING PHYSICIAN, GLASGOW MATERNITY HOSPITAL; CONSULTIN PHYSICIAN, GLASGOW HOSPITAL FOR WOMEN; EXAMINER FOI TRIPLE QUALIFICATION, GLASGOW AND EDINBURGH; FORMERLY EXAMINER, GLASGOW UNI VERSITY, ETC.

ON the introduction of high-frequency currents into medical practice a great, if not the whole, impetus came from D'Arsonval's laboratory experiments. So much did the results obtained by him lay hold upon the medical mind that men of even ordinary enthusiasm were carried away by them. What, it was asked, could high-frequency currents not do? Whilst we were assured that no harm could result from these currents we were told that by their use blood pressure fell, and then rose, remaining at a higher level, that the amount of urea was increased, that the quantity of urine became greater, that the relation of the purin bases to the urea more nearly approached to the normal where the relation had been abnormal, that the amount of exhaled carbonic acid was higher, that the muscular system was invigorated, \&c. The dramatic physical effects appealed also to the ignorant and the excitable, and so there was a boom in this new marvel of therapeutic potency. The whirligig of time, however, as usual, brought its revenge. From high hopes as to its possessing a power to do everything, disappointment followed disappointment, till it became a question with honest men whether it was, after all, worth the time and expense. Was it indeed capable of doing anything? True, some wonderful cures were effected-cures where drugs tad failed and where prolonged holidays had failed; and the conclusion seemed justified that, after all, there must be something in it, if only this something could be got out of it. This position of hopefal scientific scepticism was my own, after one or two years' experience of highfrequency currents.

The original experiments on its efficacy on the rabbit, the mouse, and the man in the laboratory had been announced in every text-book, new as well as old. I grew tired of this reiteration and asked myself what physiological effects this treatment might have on the man in the street or the invalid at home; not the physiological effects in health but the physiological effects in disease. When are these therapeutic? When are they pathological effects? How do they act not only on the same patient or in the same disease but in the same disease and the same patient in different conditions of that patient?

The question to be solved is, Why are such gratifying results obtained in some cases and why are the results so disappointing in others? The swing of the pendulum in this case must not damp us. We are all familiar with this stage in the evolution of scientific medicine. Let us simply continue to labour and to wait. My researches, in my opinion, justify me in looking towards the future of electro-therapeutics with more confidence than ever, and with the conviction that we are only now on the fringe of great possibilities. This desirable future will come all the sooner if we, individually and as a society, continue not only to wait but to labour, measuring, measuring, measuring. The early part of my work seemed to promise labour only. I seemed to be merely recording and to be unable to see any useful results from these records. They seemed either to disprove my previous assumptions or to contradict each other. Patience, however, occasionally converted a puzzle and an apparent contradiction into a new discovery, or at least a new theory which sometimes reconciled previous seeming contradictions. Science, like art, is long and life's opportunities are few, so I am, after one year of investigation, able to indicate only some of the physiological effects which in my experience have resulted from these currents in disease. I hope you will test my facts and criticise my inferences.

There has been much stir in our society and in medical journals regarding the question of restriction of electrotherapentics to members of the medical profession. In the interests of our profession and of the public I sympathise with this movement; but partly from a natural anxiety to

1 A paper read at the meeting of the British Electro-Therapeutio Society, London, on Feb. 22nd, 1907 . be always strictly fair towards rivals and opponents $I$ have never had any strong feeling of opposition towards these unqualified practitioners. I have little fear that our craft may be endangered by them. Let us only do our part towards the public with the same amount of zeal with which some of these unqualified operators do their work, and with all the advantages of scientific training and clinical experience on our side the victory is sure in the end to be ours. I feel inclined to leave the public to find out the difference between us for themselves. I confess that I am often so disgusted and impatient with their credulity that I am tempted to say, as was said of Ephraim : "They are joined to their idols, let them alone." Another word I would say regarding the illegitimate practitioner of electro-therapeutics. Before we attempt to remove the mote that is in his eye, let us make sure there is not one quite as large in our own. If he is zealous in his work and honest in his motives, and if, believing in himself. he feels proud of his many cures where "the Faculty" have failed - and in all fairness we must admit that this was often the case in the past, when electro-therapeutics was looked upon less kindly than it now is by the profession-let us not too readily thank God that we are not as he. Let us see, with all our advantages, that we are more scientific in our methods than he is. If, instead of being scientists, we are only artificers-mere switch-pullers indeed-let us see to mend our ways, and having ourselves a high ethical standard, electro-therapeutics will through us attain to its true and honourable position, whilst we as electro-therapentists will gain, in the highest sense of the term, in due time. In one point the unqualified and the legally qualified practitioners are alike, and in the present unstable position of electro-therapeutics this is pardonable-nay, it is necessary. Both are, and must be, empirics in the proper and original meaning of the term; both find by experience that electricity in certain forms cures or ameliorates certain diseases or disorders; neither can say exactly how. Of how many of our drugs may this not be said? We, however, must not remain content with this. Ours is to reason why and to find out, if at all possible, why the same treatment sometimes does good, sometimes harm, and sometimes neither the one nor the other where circum. stances are apparently similar. Since the date of introduction of the galvanometer much has been done in a scientific direction. The physiological action of electric currents can now be determined more readily, and than the determination of the physiological effects of electric current in disease no work can be more profitable and more interesting. The field is large and the work might well be apportioned amongst the members of this society. For this purpose a committee of investigation might be appointed and valuable work might be done.

Cardio-vascular system.-Few subjects have occupied the time and attention of medical scientists during the past few years more than that of blood pressure, and I have read almost everything that has been written on the subject in our medical journals. Writers differ in their mode of investigation, and, as usual, in their conclusions, yet all have agreed on the importance of this subject. I know, however, of no one who has made independent investigations and has published details of his original research in this department of medicine, from the point of view of electro-therapeutics as apart from electro-physiology. What has impressed me most of all in my study of blood pressure literature is the almost universal dread, expressed or implied, of high blood pressure. It has seemed to me to be something of a bogey to many. Only a few writers have mentioned the importance of having in certain cases a high blood pressure. One of these speaking on high blood pressure in cases of nephritis says: "I do not consider high blood pressure in itself a good thing, but I prefer to see it in the subjects of this disease." Another writes: "High blood pressure is possibly in old age a necessity for the purpose of permeating the less patent channels and stimulating more torpid cells." 2 We must not forget that a low or even in some cases a moderately high blood pressure may mean deficient cardiac force.

The more I have considered the question of blood pressure the more I have come to feel that this dangerous desire to have a low blood pressure requires to be checked. We are apt to forget that blood pressure is the product of peripheral resistance and systolic force. With a given peripheral 
resistance the greater the systolic force the higher the blood | render the records of scientific value the following five prepressure. A reduced blood pressure may mean either a cautions are necessary: (1) position of the patient and reduction of the resistance or a diminution of the force. While the former result may sometimes be desirable the latter can hardly, unless temporarily and for a special purpose, be an advantage. The danger in cases of high blood

FIG. 1

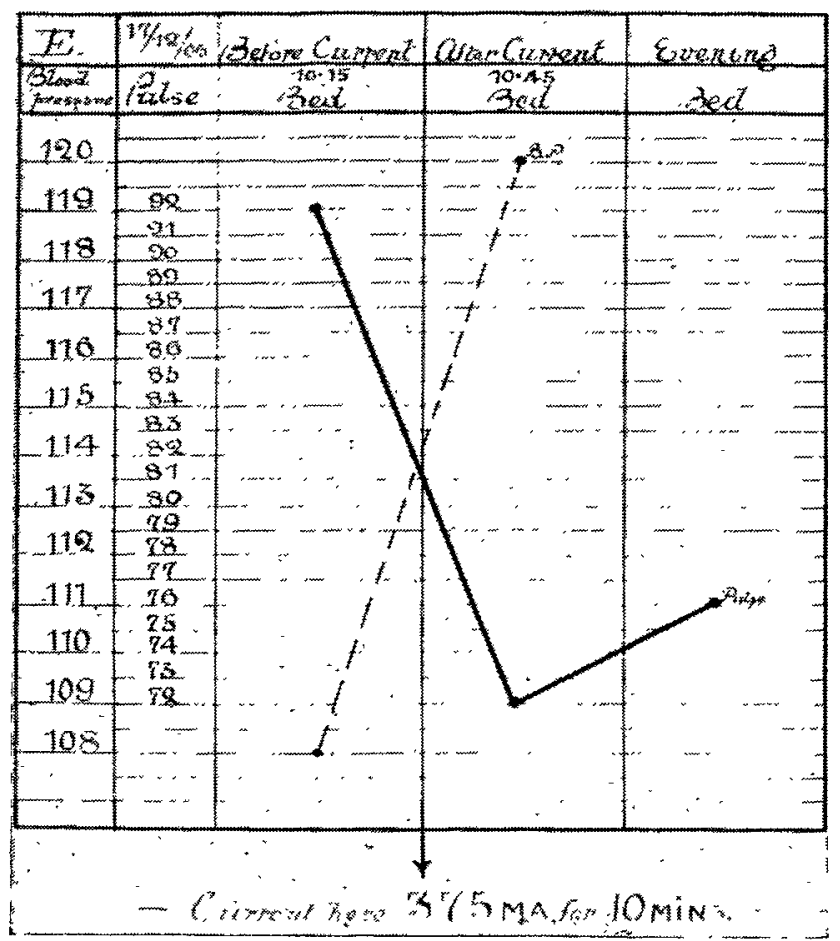

Note that the curreat here has been applied from 10.25 A.M. till 1035 A.M. The pulse was 92 ten minutes before the application, and fell to 72 ten minutes after the treatment. The blood pressure (B.P.), which was 108 before, became 120 after. These alterations of the pulse and the blood pressure indicate diminished frequency and increased force of systolic action.

pressure-I mean high relative to the age of the individual-is not in the blood pressure per se, but in the cause of this high pressure and in the fact that with it there are apt to be some weak points in the arterioles, notably of the brain, when a sudden increase of the vis a tergo may determine a fatal result. But a sudden decrease of this systolic force might quite readily cause death as surely by heart failure; especially, as I shall show might happen, after influenza. It will thus be seen that I do not consider high-frequency currents an unmixed good because they are said to cause a fall in the blood pressure any more than I consider the rise in the blood pressure which they are said to cause sometimes necessarily an advantage, since this rise might be due to increase of peripheral resistance only. You will find, however, that I have reason to dispute the statement that these currents do always, after a therapeutic dose, cause the blood pressure to fall. They frequently, in deed, do the very reverse and with much advantage to the patient. And here we see the importance of studying their physiological effects in disease. Let me here show you the apparatus which I have used for these blood pressure experiments. [Dr. Sloan here showed the Hill and Barnard pocket sphygmomanometer and the Riva-Rocci (Martin) instrument and explained his reasons for thinking the former untrustworthy, not only absolutely but also relatively. He had every confidence, however, in the latter as a means of measuring the systolic pressure.] In order to of the arm always the same; (2) same examining fingers; (3) band applied very loosely ; (4) several records taken before current applied; and (5) records taken for each case at the same hour, if possible.

Important changes are sometimes observed in the pulserate. Physiologists state that, as a iule, a low blood pressure is accompanied by a quick pulse, and according to mechanical laws one would expect this. I find, however, that in disease this is mainly temporary, the cardio-vascular mechanism adjusting itseif sooner or later, according not only to the individual but according to the then condition of the individual. Where the heart becomes seriously disabled the high blood pressure causes a rapid pulse, rapid in proportion to the height of the peripheral resistance and to the degree in which the heart is unable to meet the demand made upon it. I might explain how the polse-rate is affected under different conditions of peripheral resistance by the following analogy. Let us suppose that three men are required to walk a certain distance in the same time, each being at liberty to choose his own length of step, one taking short and frequent steps, those of another being longer and less frequent, but all going at the same pace. Suppose one of these men to be of ideal strength with abundant neuro-muscular reserve, the second a man of only moderate strength, and the third distinctly below the average in staying power. They are walking against a moderate head wind when suddenly the wind abates. The first man is hardly conscious of any difference in his pace and an onlooker would probably observe no change in it. The second man, when the wind abates, has to step out somewhat more quickly till he recovers himself, when he resumes his ordinary pace, whilst the third man, unless he has been warned of the change in the force of the wind, has to run for some steps and almost falls forward on account of his difficulty of at once adjusting himself to the sudden change. Let the head wind as suddenly increase, and whilst no effect is apparently produced on the pace of the first man the second one will take longer and less frequent steps for a few seconds till he finds what pace will enable him to progress at the required rate with least fatigue. The third man again may even miss a step before he recovers himself. This analogy of the muscular effort of walking against a varying wind resistance in front, to a heart acting against a varying arteriolar resistance is a useful one, and although analogies must not be pushed to an extreme it is as close a one as I can think of. Thus the pulse-rate will depend upon the condition FIG. 2.

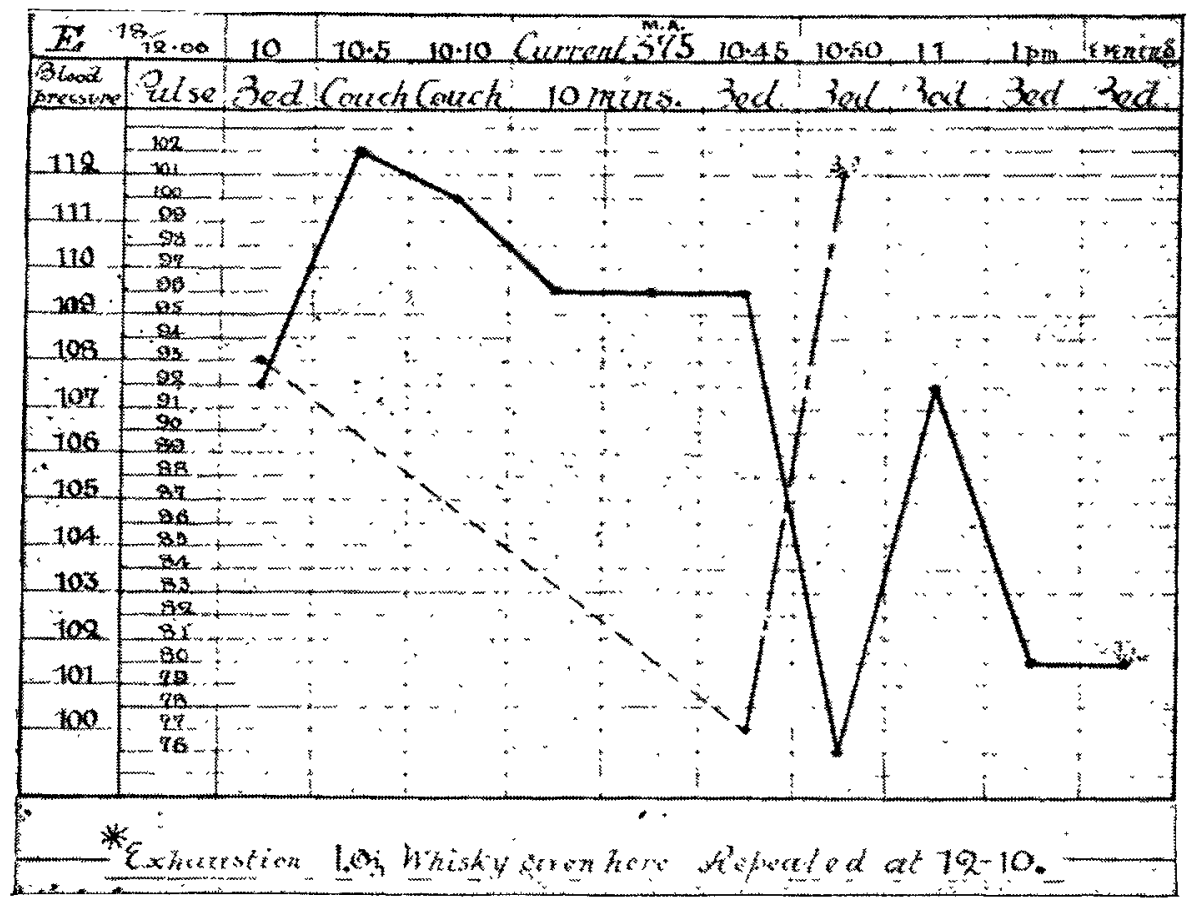

Note here the effect of the exertion of going from the bed to the couch in raising the pulse rate from 92 to 102 . This was largely owing to previous mental excitement. The result is at first a dangerous lowering of the blood pressure from 108 to 100 , though afterwards the blood pressure rose to 112 and the pulse rate fell to 76. An asterisk has been omitted in this figure above the point indicating the pulse rate at 10,45 A.M. 
of the cardiac force when the arteriolar resistance varies, at least for a shorter or longer interval after the change of resistance. If the arteriolar relaxation is sudden and the asthenia severe or increased by previous undue exertion the heart may be even seriously hampered. The blood pressure will in these circumstances give an indication of the amount of cardiac reserve. If the heart's energy is only slightly diminished it will maintain the blood pressure at its initial height in virtue of the tonic effect of the current upon it if the dose has not been so strong as to cause excessive relaxation of the arterioles, the relaxation of the arteriolar resistance being exactly counterbalanced by the increase of the cardiac force. I shall give the evidences of this tonic effect on the heart when I come to explain the charts. Should the arteriolar relaxation be excessive the blood pressure may rise, but only if the current is suited to the case and the cardiac force is increased at a greater rate than the arteriolar resistance has been reduced.

FrG. 3.

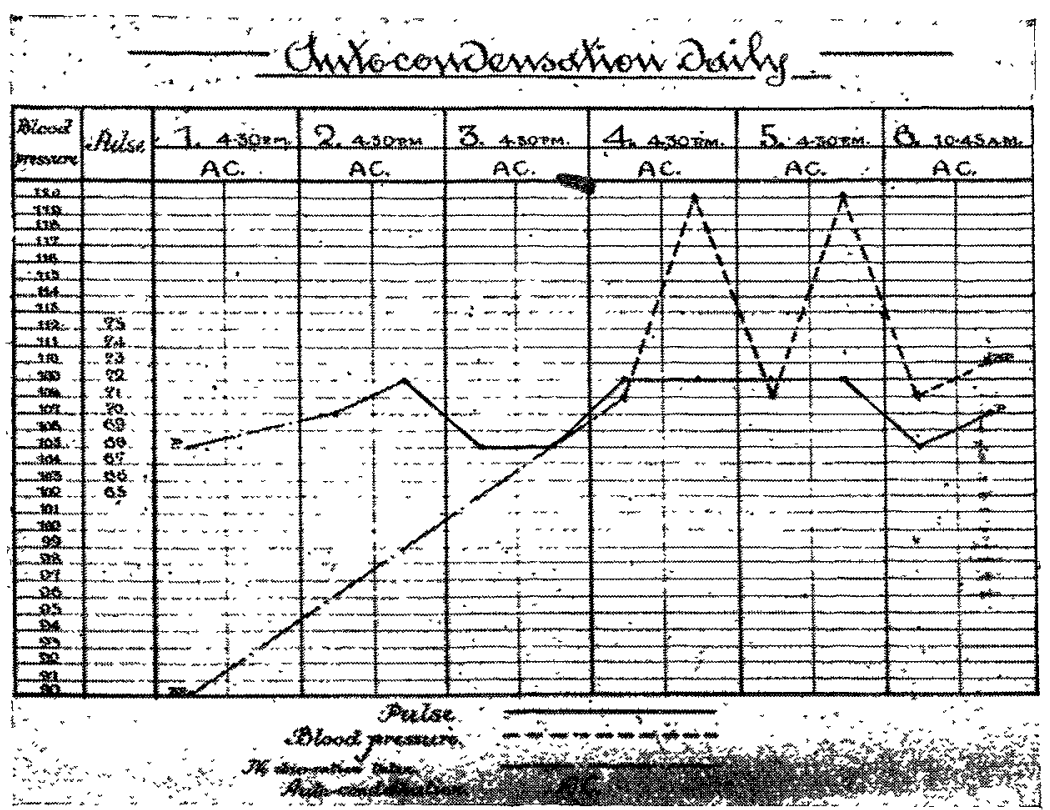

Here the blood pressure has risen, on account of improvement in the cardiac force, from 90 at the beginning of the treatment to 110 at its close.

TABLE I

\begin{tabular}{|c|c|c|c|c|c|c|}
\hline No. & \multicolumn{2}{|r|}{ Heart. } & \multicolumn{2}{|c|}{ Arterioles. } & $\begin{array}{c}\text { Blood } \\
\text { pressure. }\end{array}$ & $\begin{array}{l}\text { Blood } \\
\text { flow. }\end{array}$ \\
\hline 1 & Force & constant. & \multicolumn{2}{|c|}{ Resistance increased. } & + & - \\
\hline 2 & ," & " & & diminished. & - & + \\
\hline 3 & & increased. & , & constant. & + & + \\
\hline 4 & & diminished. & " & " & - & - \\
\hline 5 & & increased. & , & diminished. & +- & $+t^{*}$ \\
\hline 6 & & diminished. & $n$ & increased. & -+ & $--\dagger$ \\
\hline 7 & " & increased. & ," & , & ++ & +- \\
\hline 8 & & diminished. & & diminished. & - & -+ \\
\hline
\end{tabular}

As bearing on the question of the physiological effect of alterations of cardiac force and of arterial resistance the accompanying table from Waller ${ }^{3}$ (Table I.) will be interesting and may be helpful. The only portion of this table to which I shall ask your attention at present is combination No. 5. It is obvious that with this combination the effect on the blood-pressure will depend on the relation which the increase of the cardiac force bears to the decrease of the peripheral resistance. No mention is made in Waller's table as to the effects on the pulse-rate and I cannot find any information on this subject from text-books on physiology. A professor of physiology whom I consulted told me that the question was too involved for him to be able to answer it. I have thought it well, therefore, to draw up the following

3 Human Physiology, third edition, p. 59. few out of many possible equations, which may help to elucidate this, as well as to show some of the effects on blood-pressure. These, I claim, are reasonable deductions from my charts. It is to be noted that all possible combinations of increase of cardiac force and decrease of peripheral resistance result in an increase of blood-flow. Let $x$ equal unit increase of cardiac force. Let $y$ equal unit decrease of peripheral resistance. Then the immediate effects are :-

$$
\begin{aligned}
& x+y=\text { change of blood-pressure, } 0 \text {; change of pulse-rate, } 0 \text {. }
\end{aligned}
$$

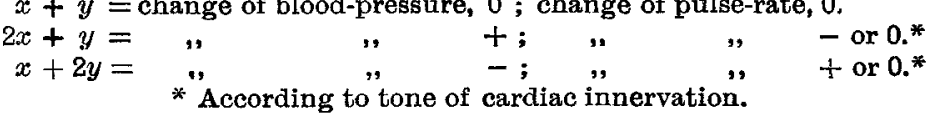

These remarks may pave the way for the following details as to the conclusions to which $I$ have come regarding the effects on the pulse and the blood pressure by these highfrequency currents. I shall illustrate them by screen views of actual results obtained. 1. These currents cause in all cases at first diminished peripheral resistance. 2. In all cases this is followed sooner or later by increased cardiac force when the currents are given in therapeutic doses. 3. The effects on the blood pressure and the pulse-rate of this double action will depend on the cardio-vascular stability. 4. Should this be normal, there may be no change whatever in either the blood pressure or the pulserate; only, as may be seen from Waller's table, an increase of blood flow, giving rise to slight elevation of the temperature of the blood. 5. Should there be slight cardio-vascular instability then the diminished peripheral relaxation is only in part compensated by the heart, and so the blood pressure falls slightly and there may be no change in the pulse-rate. (See Table II. (a).) 6. On the other hand, should the heart be in a state of asthenia and the blood pressure have been already low on this account, then, if the patient on reaching the couch is for him fairly fresh, there having been nothing to depress or to fatigue just before the treatment, the increase of the cardiac force obtained from the current may so. overpower the tendency to peripheral relaxation that the blood pressure rises whilst the pulse-rate falls. (See Fig. 1.) 7. Again, should matters be as in the last case with the exception that the patient has recently been fatigued or unduly excited the heart may be unable to respond to the action of the current, just as the breeze which will fan a steady flame may extinguish a flickering one. The heart may be at first staggered, the cardiac force failing to rise to the occasion; the result will be a dangerous fall of the blood pressure with a relatively high pulse-rate. Any immediately succeeding fatigue, though moderate, may in such a case give rise to the need for stimulants. (See Fig. 2.) 8. The after-effect is, in low blood pressure due to diminished cardiac force prior to the treatment, a higher level of blood pressure. (See Fig. 3.)

\section{TABLE II.}

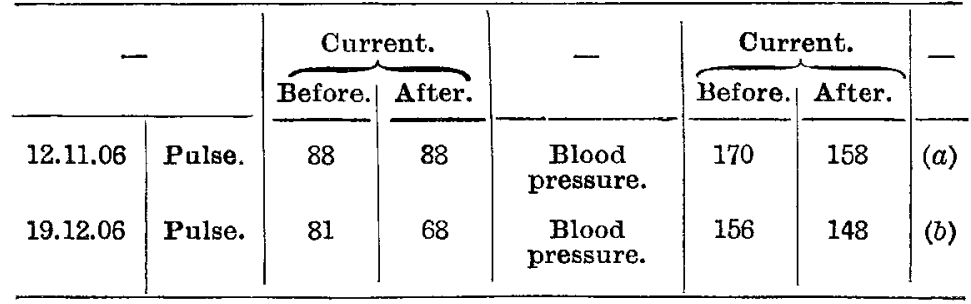

12 applications from 12.11.06 till 19.12.06.

In this case the age of the patient was 57 years, and the blood pressure, which I took several times to insure accuracy, was so low as to be unique in my experience for that age. With the rise of the blood pressure under the electric treatment the attacks of faintness ceased and the patient's health was completely restored. 9 . If the blood pressure be already high, due to the high arterial resistance of albuminuria with somewhat weakened cardiac action, the current will probably have the effect of raising the blood pressure without raising the rate of the pulse. (Table III.) Where the above is the case and from long illness the cardiac asthenia is great, as shown by a high pulse-rate which no medicine is able to reduce, the beneficial effect on the pulse-rate is 
TABLE III

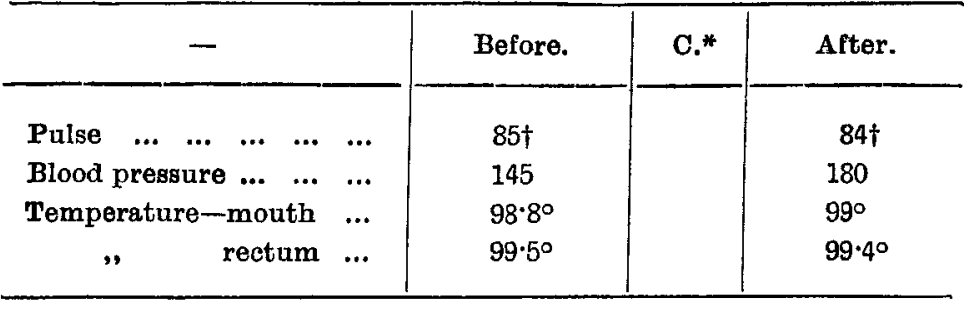

* Current 300 milliampères for 10 minutes.

$\dagger$ Soft and small before; much fuller after.

sometimes striking. One such case will be referred to in the part of this paper dealing with the urinary excretion showing the remote effect of the improved cardiac force on the kidneys. 10. When the blood pressure has been high for the individual's age and there is no

TABLE IV.

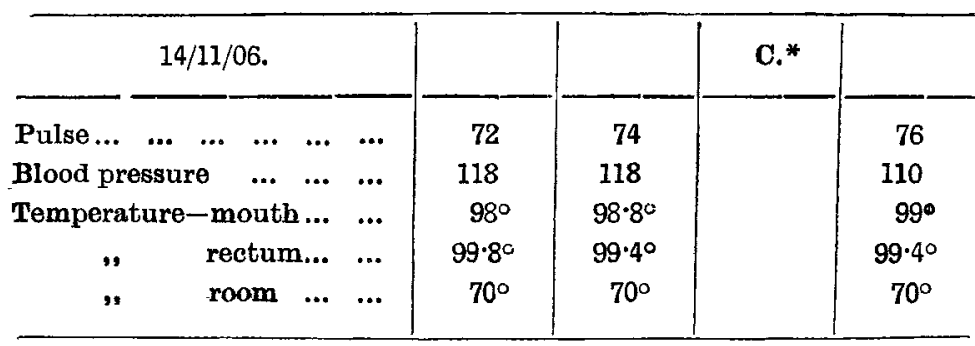

* Auto-condensation current 500 milliampères for 15 minutes. Two observations of pulse, \&c., were taken before current was turned on.)

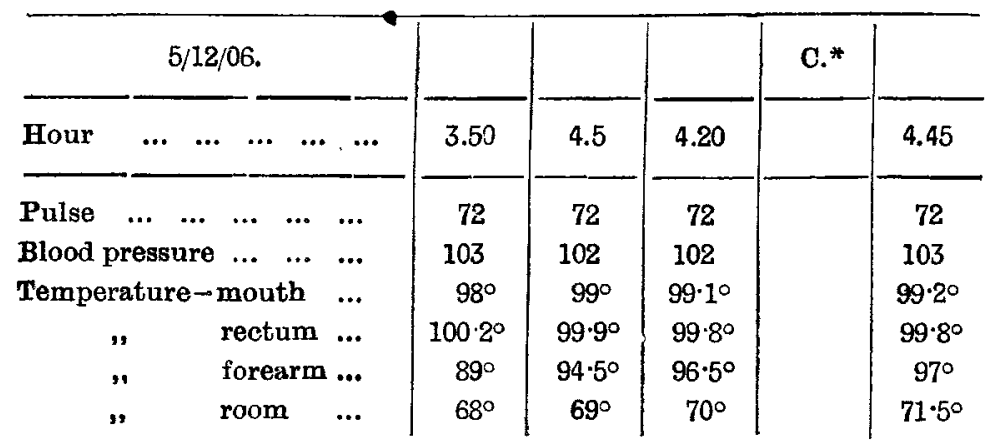

* Auto-condensation current 500 milliampères for 15 minutes. Age of patient 29 years.

apparent disease to account for it, I have observed that after several applications of the current the blood pressure is diminished and there is a corresponding improvement in the pulse-rate. (See Table II. (b), also Table IV.)

I shall show you presently the effect on the rhythm of the pulse in the case referred to in Table II. 11. In some instances of intermittent pulse-radial only or cardiac as well-the intermissions may diminish or disappear, although as in one case this intermittent pulse had caused anxiety to the patient for many years. Should the intermission have existed for a short period only, as from temporary gastro-intestinal disorder, the intermissions of the pulse may cease after two or three applications of the current; probably from the beneficial effects of the current on the gastro-intestinal canal. A very interesting case of intermittent pulse came under my notice about the beginning of the present researches. The patient was "run down" and she was "nervous." So weak was she and so unstable seemed the cardiac innervation that, although $I$ knew that her object in coming to see me was to get electric treatment, I decided first to put her under bromide of potassium and tincture of nux vomica. At her next visit to me there was no change in the pulse condition, there being still about ten intermissions per minute. Auto-condensation was given for $\mathbf{1 5}$ minutes, the pulse-rate fell, and during the following 90 seconds no intermission was detected. The number of intermissions per minute had decreased at her next visit to me four days later, and they again disappeared after 15 minutes of the current. Afterwards the pulse is always noted as regular. A notable condition in this case was that at the early part of the treatment the temperature in the mouth and in the rectum was subnormal, the former being usually under $97^{\circ}$ and the latter under $99^{\circ}$. By the end of the treatment the temperature in both the mouth and the rectum became nearly normal.

I think after what I have said regarding the tonic effects of high-frequency currents on the heart I need hardly adduoe further evidence of my contention. I have dwelt on this fully because I consider it of the greatest importance, and $I$ think you will agree with me in this. As bearing on this, however, and also on the much-debated question as to the comparative value of the living fingers as against dead, though mechanically more perfect instruments for gauging the condition of the pulse, I may say that the only times I have been impressed with the fact that I was having under my finger a full pulse, as a contrast to what it had been before, was at the close of an antocondensation and before I knew that my watch and my sphygmomanometer were going to register a lower rate of pulse and a higher blood pressure than before the application of the current. One other point I shall merely mention. Where the pulse is variable before the current application it may become quite regular and steady immediately after. On one occasion the rate varied between $\mathbf{7 0}$ and 84 per minute, whereas it was 78 and absolutely steady in its rate immediately after the couch treatment. Some confusion in judging of the influence of the current on

TABLE V.

\begin{tabular}{|c|c|c|c|c|c|c|c|c|}
\hline $\begin{array}{llll}\text { Hour } & \ldots & \ldots & \ldots\end{array}$ & 5.27 & 5.38 & 5.50 & 5.58 & 6.4 & 6.10 & 6.15 & 6.23 \\
\hline$\ldots$ & 84 & 84 & 84 & 84 & 84 & 84 & 80 & 80 \\
\hline Blood pressure ... & 240 & 215 & 185 & 185 & 182 & 185 & 185 & 180 \\
\hline
\end{tabular}

Current 400 milliampères from 6.5 till 6.20 .

e blood pressure is apt to arise where the effect of immediately preceding exertion or excitement has been to raise the blood pressure and to lower the pulserate or raise it before application of the current. In the former case the heart has been quite able to respond to the exertion and so becomes slower. In the latter it has not, but has to beat faster on account of the fatigue. (Fig. 2.) If no change has taken place in the fulse-rate-this having been normal before-a good opinion may be formed of the cardiac force. (See Table V.) This case and cases where the pulse-rate is high, owing to nervous dread of the physician, show the

FIG. 4.

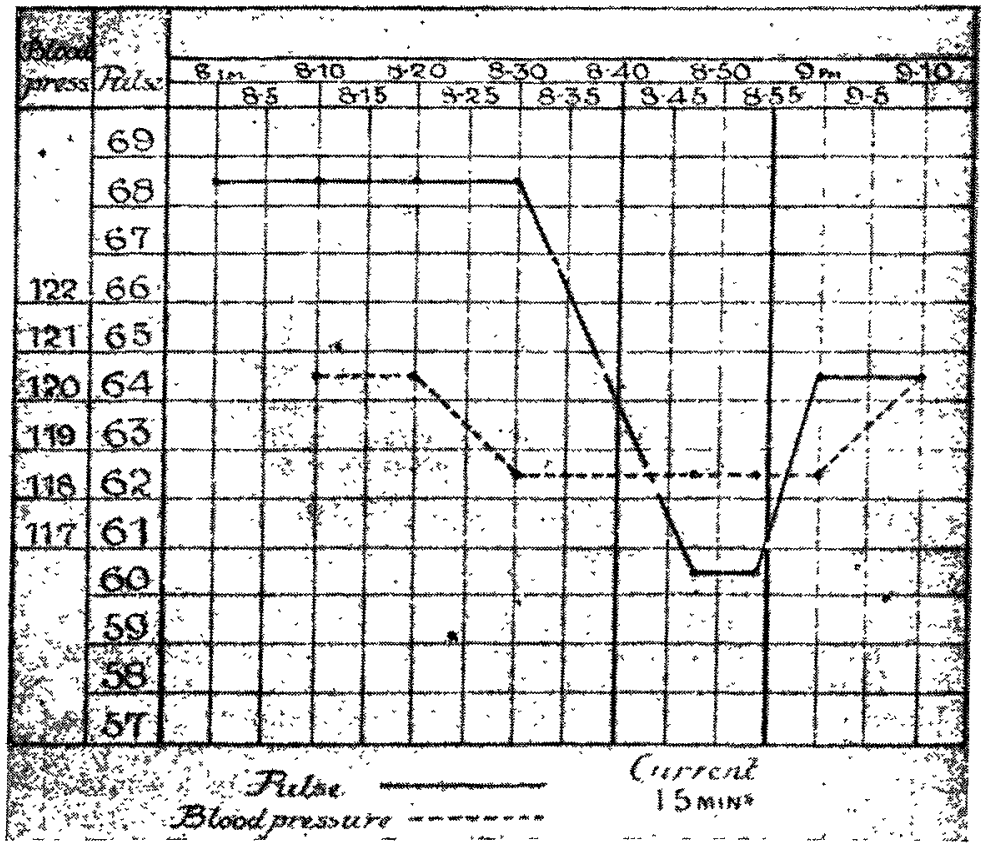

importance of allowing sufficient time for restoration of the cardio-vascular status quo before any conclusion can be come to regarding the effect of the current on the blood pressure and on the pulse-rate in any particular case. If a 
rise of blood pressure and a fall of pulse-rate result from previous exertion a fairly good dose of the current may be given, the final result being probably a lower pulse-rate, with no change in blood pressure. In the case shown in Fig. 4 the tonic effect on the heart is evidenced by a lowering of the pulse-rate without any reduction of the blood pressure. ${ }^{4}$ If, however, a rapid pulse be the result of very slight exertion and the blood pressure not have been high, danger

FIG. 5.

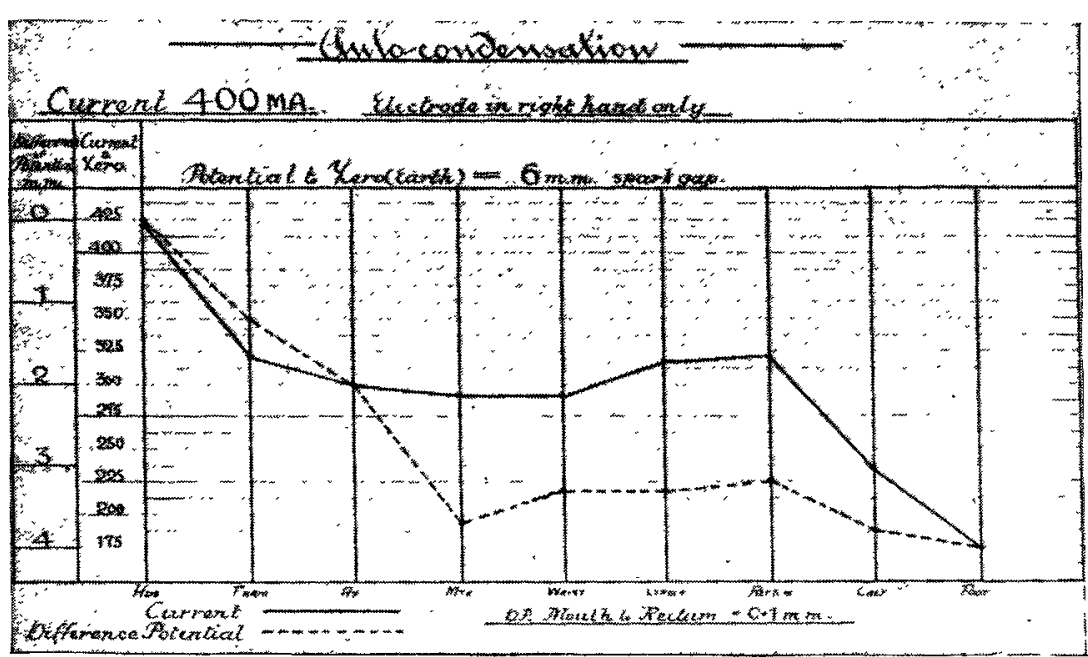

but purely physical. For examples of local rises of temperature see Tables VI. and VII. The difficulty of determining the physiological production of heat is stated very clearly by Waller. ${ }^{5}$ He says: "By the thermometer we ascertain the temperature of the body, not the amount of heat that it produces or loses. The thermometer gives no measure of the activity of heat production, nor even any positive indication that it is above or below the normal. This must obviously be so when we reflect that the amount of heat in a given body and consequently its temperature, is the resultant of two factors-heat production and dissipationeither or both of which may vary. Theoretically, of course, temperature varies directly with the amount of heat produced and inversely with the amount of heat dissipated, but practically the thermometer does not show whether more or less heat is being produced or dissipated." We are thus left in great part to infer a heat production in the blood by these currents rather than to test it by the thermometer. Here let me state what may not have occurred to some of you, that whilst the rectal temperature is the internal tem. perature proper, being that of the large splanchnic storehouse of heat, that of the mouth, as pointed out by Haig, is a peripheral temperature. On starting $\mathrm{my}$ investigations I allowed too little time for heat distribution consequent on the recumbent position of the patient. In fact, I did not know of it then. When $I$ found, therefore, that at the end of the séance the mouth temperature had risen

may follow even a moderate dose, unless the time be materially shortened (Fig. 2). Should the pulse rise as soon as the current is turned on the patient if asked will probably complain of faintness towards the end of the application, there being a delay of a few minutes in the increase of the cardiac force. The tonic effect on the heart, however, will appear later by the fall in the pulse-rate and the rise in the blood pressure. I may mention here incidentally that in my experience the best results from electric treatment in any form are obtained after all the benefit possible has been derived from drugs and these have failed materially to benefit the patient and when sufficient rest has been taken before each application and for an hour or so after. The best time for a change of air so as to complete the recovery is after the conclusion of the course of electric treatment.

Immediate thermio effeots. - We are all much indebted to my fellow-townsman, Dr. W. F. Somerville, for his investigations into the problem of surface heat production as a result of high-frequency currents. These are so complete and so firmly established that I need not dwell on them, nor trouble you with my own results more than is necessary to prove what, in my opinion, is the cause of them, and to show that these thermic effects are in no way physiological,

TABLE VI.

\begin{tabular}{|c|c|c|c|c|c|c|c|c|c|c|}
\hline \multicolumn{4}{|c|}{ Time. } & 2.30 & 2.40 & 2.50 & 3 & C.* & 3.20 & 3.25 \\
\hline \multicolumn{4}{|l|}{ Temperature- } & & & & & & & \\
\hline Mouth & $\ldots$ & $\cdots$ & $\ldots$ & $98.5^{\circ}$ & - & $98 \cdot 2^{\circ}$ & - & & $98 \cdot 2^{\circ}$ & - \\
\hline Axilla & $\ldots$ & $\ldots$ & $\ldots$ & $98^{\circ}$ & - & $97 \cdot 8^{\circ}$ & - & & $99 \cdot 2^{\circ}$ & - \\
\hline Forearm & $\ldots$ & $\ldots$ & ... & - & $90^{\circ}$ & $91 \cdot 4^{\circ}$ & $92^{\circ}$ & & $94^{\circ}$ & $93^{\circ}$ \\
\hline Room & $\ldots$ & & $\ldots$ & $61^{\circ}$ & - & $64^{\circ}$ & - & & $66^{\circ}$ & - \\
\hline
\end{tabular}

* Auto-condensation current 450 milliamperes for 15 minutes. TABLE VII.

\begin{tabular}{|c|c|c|c|c|c|c|c|c|}
\hline Time. & & 4.40 & 4.45 & 4.50 & 4.55 & c.* & 5.20 & 5.30 \\
\hline \multicolumn{9}{|l|}{ Temperature- } \\
\hline $\begin{array}{lll}\text { Mouth } & \ldots & \ldots\end{array}$ & $\ldots$ & - & - & - & $98.4^{\circ}$ & & - & $98 \cdot 4^{\circ}$ \\
\hline Rectum $\ldots . .$. & $\ldots$ & - & - & - & $99 \cdot 2^{\circ}$ & & - & $98.9^{\circ}$ \\
\hline Right forearm & $\ldots$ & $90^{\circ}$ & $93^{\circ}$ & $94^{\circ}$ & $93^{\circ}$ & & 96.50 & - \\
\hline Left forearm ... & $\ldots$ & $90^{\circ}$ & - & $92 \cdot 5^{\circ}$ & - & & $94^{\circ}$ & - \\
\hline
\end{tabular}

* Auto-condensation current 480 milliampères from 5.5 to 5.20 . Electrodes in both hands.

4 See Causes of Variation in the Blood Pressure, "Circulation and Respiration," Lauder Brunton, first series, 1906, p. 273. on an average one degree and the rectal had fallen one degree I came to the conclusion that this was the effect of the current, by relaxation of the peripheral vessels. In one instance-a case of nephritisexactly the opposite change had resulted, why I cannot tell; but amongst the many I have tested it is the only exception. After some control experiments I discovered that the transfer of heat from the internal to the peripheral circulation was natural and in no sense electro-physiological. A considerable amount of time, FIG. 6 .

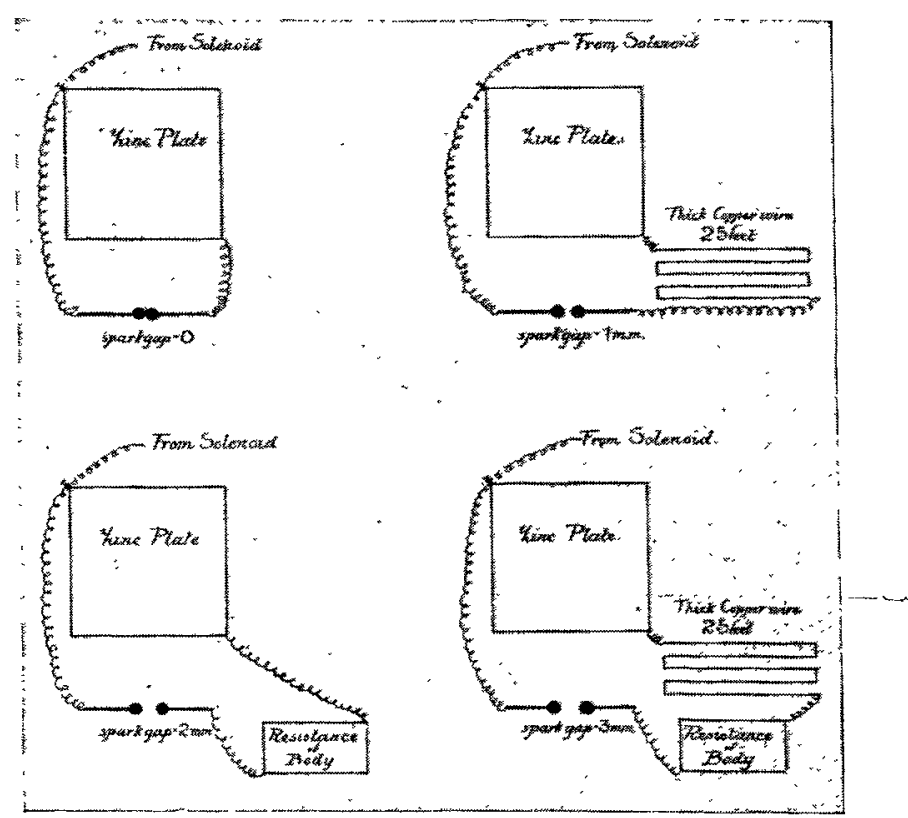

This figure shows that all parts of a metallic plate are at the same potential; whereas the difference of potential between the plate and the end of a 25 feet long thick copper wire attached to it is considerable. This is increased should the patient's body intervene also.

I find, is required to bring about this state of heat equilibrium, something like from 30 to 40 minutes. This gives time also for determining to what extent heat reduction is taking place. This latter will depend on previous exercise and the time of the patient's last meal. Physiologists are evidently agreed that the greatly 
reduced morning temperature, internal and peripheral, is wholly due to diminished heat production consequent upon long rest. If the blood temperature as ascertained in the mouth and rectum has been diminishing before the current was applied and is found to be stationary during the time of the current, the natural inference is that the current bas had some share in this by causing increased heat production. My researches have pointed in this direction, but I have little of definite proof to bring forward in support of it. Waller's statement may explain this. It will be a natural inference also that the heat distribution I have spoken of will account for the rise in the surface temperature throughout as well as in that of the mouth. There is evidence of this contention in the heat tables I now show you, as an explanation of some at least of Dr. Somerville's results. In no case where I have allowed sufficient time to elapse before turning on the current has there been anything like such a rise as he, in some cases, has found. (See Tables VI., VII., and VIII.)

\section{TABLE VIII.}

\begin{tabular}{|c|c|c|c|c|c|c|c|}
\hline \multicolumn{2}{|l|}{ 一 } & \multicolumn{4}{|c|}{ Intervals of ten minutes. } & \multirow[t]{2}{*}{ C. * } & \multirow{2}{*}{$\frac{\begin{array}{c}\text { After } \\
\text { current. }\end{array}}{78^{\circ}}$} \\
\hline Foot... & $\ldots$ & $78^{\circ}$ & $79^{\circ}$ & $79^{\circ}$ & $78^{\circ}$ & & \\
\hline Groin & ... & $96^{\circ}$ & $96.8^{\circ}$ & $97^{\circ}$ & $97 \cdot 1^{\circ}$ & & $97 \cdot 7^{\circ}$ \\
\hline Rectum. & ... & $99 \cdot 2^{\circ}$ & $992^{\circ}$ & $99 \cdot 1^{\circ}$ & $98 \cdot 8^{\circ}$ & & $99^{\circ}$ \\
\hline Forearm . & ... & $94^{\circ}$ & $948^{\circ}$ & $94 \cdot 7^{\circ}$ & $94 \cdot 7^{\circ}$ & & $98^{\circ}$ \\
\hline Axilla & $\ldots$ & $98^{\circ}$ & $98^{\circ}$ & $98^{\circ}$ & $98^{\circ}$ & & $98 \cdot 2^{\circ}$ \\
\hline Mouth & - $\ldots$ & $98 \cdot 8^{\circ}$ & $98.6^{\circ}$ & $98^{\circ} 4^{\circ}$ & $983^{\circ}$ & & $98 \cdot 6^{\circ}$ \\
\hline
\end{tabular}

* Auto-condensation current 500 milliampères for 15 minutes.

During Current.

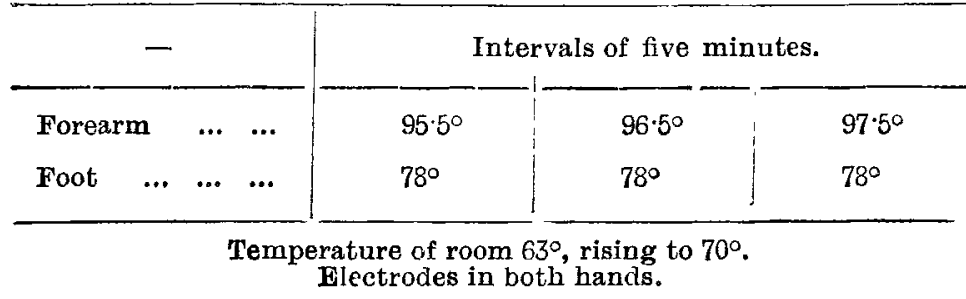

It will be noticed that the greatest increase of heat is near the electrodes, and this increase of heat diminishes in amount in proportion, as a rule, to the distance of the parts tested from the electrodes. It is plainly not blood heat, but only surface or superficial tissue heat. Table IX. is a good

TABLE IX.

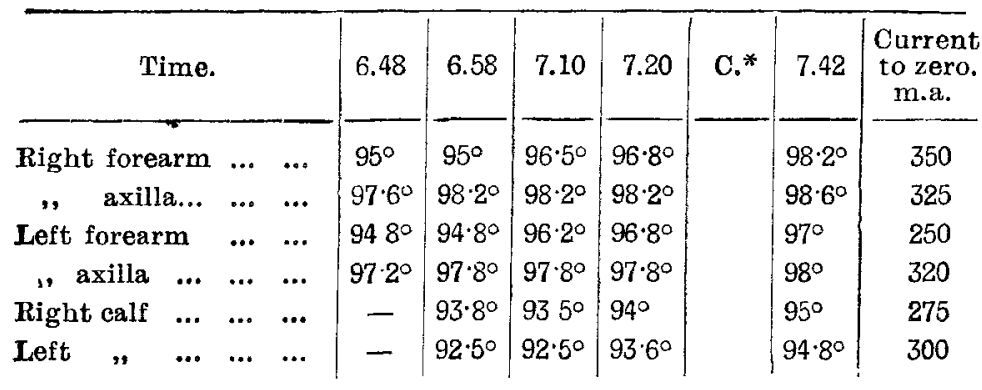

* Auto-condensation current 500 milliampères for 15 minutes. Observations begun after having been one hour in warm room. Electrodes in right hand and on left foot.

example of this, the electrodes having been in the right hand and on the left foot. In some of my observations the temperature in the axilla is actually higher than that of the mouth. The only time I have ever observed this, apart from the action of the current, was when a patient came to see me one cold night and I found the temperature in the axilla $98^{\circ}$, whilst that of the mouth was $97.7^{\circ}$. This, however, was obviously due to the fact that he was in part a mouthbreather and had left at home his artificial teeth, as these were uncomfortable. As soon, however, as the warm atmosphere of the room had time to tell the mouth temperature became $98 \cdot 6^{\circ}$. Now, how are these increased surface temperatures caused? I have pointed out that they are greater the nearer the parts tested are to the electrodes, and you will see that this is, by physical laws, just what might be expected, since the current to earth is greatest there and the local heat will be directly proportioned to the square of the current It must be borne in mind that the quantity of the electricity in the case of the static form is proportioned only to the capacity of the part; whereas in high-frequency applications the current decreases in proportion to the distance of the parts from the electrodes and to the difference of the potential between these and the points from, which we are measuring it. (See Fig. 5.)

The heat production is the product of the resistance, as measured by the difference of potential, into the square of the current, and the closer these points of potential difference are to each other in proportion to the amount of potential difference the greater will be the heat concentrated there. This is, of course, a purely physical law ; and it can easily be seen that, considering the enormous ohmic resistance of the dry skin, this resistance might quite equal a sparkgap of one to two millimetres between the hand and the forearm, as you can see is the case in some of the charts. That distance, as well as ohmic resistance, determines the length of the spark-gaps, and therefore the amount of the current from various points to zero is shown in Fig. 6 . Of course, we must remember that although the heat production is directly increased by the potential difference, yet as this increases it will be seen that the current decreases, and so the heat production is less in spite of the resistance being greater, since the current has more influence than the resistance in causing heat.

I need hardly say anything as to how the amounts of this potential difference and current to zero are obtained. The points from which the potential difference is to be measured should have a metallic connexion to either side of a spinthermeter for the former. The current to zero is measured by making a metallic connexion from any part to earth with a milliampèremeter inseries. With both hands on the ordinary electrodes it would be seen that the largest amount of current is, as might be expected, from the hands. The next in amount of current of those measured is from the forearm, and the potential difference between the hand and the forearm is quite considerable, varying from one millimetre to two millimetres, so that nearly the full amount of the current from the hand must act on the wrist and lower forearm. (See Fig. 5.) That the lines of the potential difference and of the current tozero in this chart do not quite run parallel is due, I suspect, in part to the fact that all the potential difference records are taken at one time and then all the current records. This will result in the points of each region from which the readings are taken not being exactly the same. The potential difference and the current may differ in various cases, but though this will in part depend on the ohmic resistance it also depends, at least in the case of the potential difference, on the initial total potential difference -that is, length of spark-gap from hands to earth, the same quantity of current being obtainable from the same apparatus and on the same individual by different arrangements of solenoid and spark-gap, but with a different amount of total initial potential difference to earth. (See Fig. 7.) Query, what, if any, difference therapeutically will there be from the same amount of current but at different voltages? This I have not had time to test.

I have no doubt that some of the rise of temperature in the mouth and in the rectum must be electro-physical, but how much it would be difficult to say. I should expect, however, that this would tell more on the mouth temperature than on that of the rectum, when the electrodes are grasped by both hands. Like Dr. Somerville, I have noticed that the increase of heat on the left forearm is less than that on the right. The cause of this $I$ find is that the resistance is usually greater, and the current to zero less, in the left than in the right forearm. For obvious reasons the reverse would probably be the case in left.handed people.

Penetration of the currents into the deeper tissues.-I have already taken up so much time with the part of my thesis bearing on the cardio-vascular system that I must be brief with the remaining departments outlined in my synopsis. On another occasion I may return to them. It has been generally assumed that high-frequency currents are confined practically, if not wholly, to the surface, and that their physiological effects arise from their action on the peripheral nerves and the peripheral circulation. Dr. H. Lewis Jones, in his admirable text-book on "Medical Electricity," contests the truth of this assumption, basing his argument on the physiological results being such as to require for their explanation 
a deeper action of the currents. My researches have quite convinced me that there is abundant evidence of Dr. Jones's contention from the electro-physical standme say that if anyone doubts the fact that these currents traverse the neuro-muscular apparatus, let him, with one hand holding one of the usual couch electrodes, place

FIG. 7.

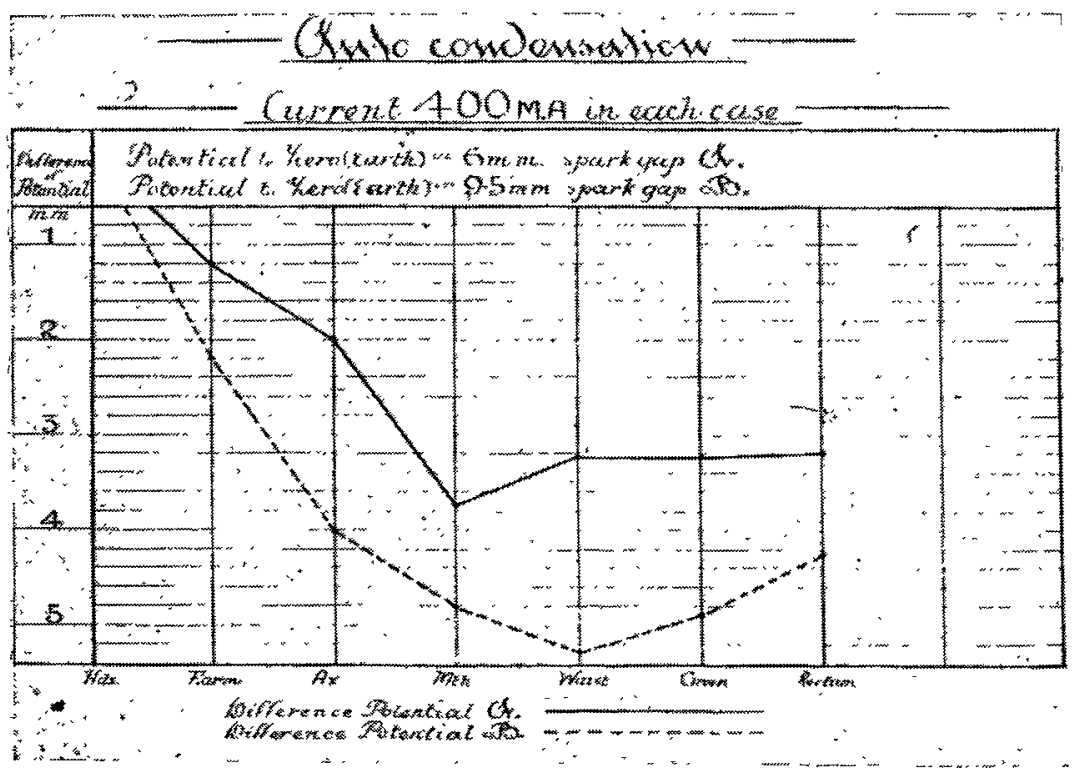
point. Before going into this matter, however, let

times as great as that between the mouth and the rectum: that is to say, the resistance and the distance between the mouth and the rectum are not those by the chin, neck, breast, and abdominal walls, but by the gastro-intestinal tract. Again, the potential difference between the axilla and the groin is less than that between the axilla and the waist. Why, indeed, unless the current has gone from the axilla to the groin not simply by way of the body wall but also by the gastro-intestinal canal. I have come to suspect indeed that it takes an even easier road-namely, by the thoracic and abdominal viscera direct, as well as by the gastrointestinal tract. For if by the latter route only, then, though the obmic resistance is not great, it is greater than that of a No. 14 copper wire, and the distance is quite as long as 25 feet. Yet we see how large a drop of potential this wire caused. (Fig. 6.) The amount of current to zero at the mouth and at the rectum is almost as if these were different parts of a metallic plate over which the current is flowing easily. Since the current is thus seen to be acting on the whole lining membrane of the alimentary canal there is no wonder that this electric energy has an influence on the appetite and on the general health.

Effects on renal excretion.-My researches in this department have, like those in connexion with the cardio-vascular system, led to a good deal of confusion and uncertainty; and although in the case of the latter I think I have been able to bring some order out of this confusion, I am not quite sure that this has been so in the present department of this work. It will readily be seen that the difficulties are

another electrode held by an insulated handle on the upper portion of the sterno-mastoid muscle and with metallic connexion to the hand electrode, a small spark-gap only intervening, and he will have sensible demonstration of the fact. An objection to this will probably be made that it is the spark which is causing this and not the current from the hand to the neck. Well, let anyone try this experiment without any flow of current by letting go the hand electrode but retaining the spark-gap to the connexion between the couch terminal and the neck, and he will find that so long as he holds the hand electrode so long will there be muscular response, but as soon as he lets go the handle no muscular contraction will occur, although the connexion still exists. Let the gap be so wide, however, that no sparking occurs, then no muscular contraction occurs. The eurrent from the hand to the neck requires to have its potential and the amount of its current disturbed by the varying condition of the outer spark-gap circuit. If an additional argument were required that it was the current from the hand to the neck which was causing the disturbance, it might be found in the fact that as soon as the neck electrode is applied contraction of the muscles of the forearm is set up as well. Another objection which might be raised is that the current causing the muscular contraction is not a pure high-frequency current. If by that is meant that when high-frequency currents are pure they do not cause muscular contraction, I admit this. All the same, however, they are high-frequency currents, the only difference being that at the time they are suffering from a frequent change of potential, through the irregular action of the spark-gap, just as the unidirected current causes muscular contraction only when its potential is changed. In the latter case, however, it is not contended that since there is no muscular contraction during the steady flow of the current there is therefore no current reaching and passing through the muscle. The electro-physical evidence will, I think, appeal to you without much argument from me. A mere statement of some facts, indeed, and an explanation of these by means of Fig. 5, will, I think, satisfy you.

I have referred to the fact that the potential difference varies according to the resistance and in proportion to the distance from the entering current. You see that it may amount to about one millimetre at the forearm, two millimetres at the axilla, three millimetres at the waist, three millimetres at the groin, and four millimetres at the foot. If you examine this chart, however, you will find that the potential difference from the hand to the mouth is practically the same as that from the hand to the rectum; now the potential difference between the neck and the groin is five greater. In the laboratory experiments absolute rules as to diet can be, and must be, enforced; whilst in the case of patients such rules are difficult, if not impossible, to enforce, and, if possible, not generally desirable; the tastes

$\mathrm{FIG}_{2} 8$.

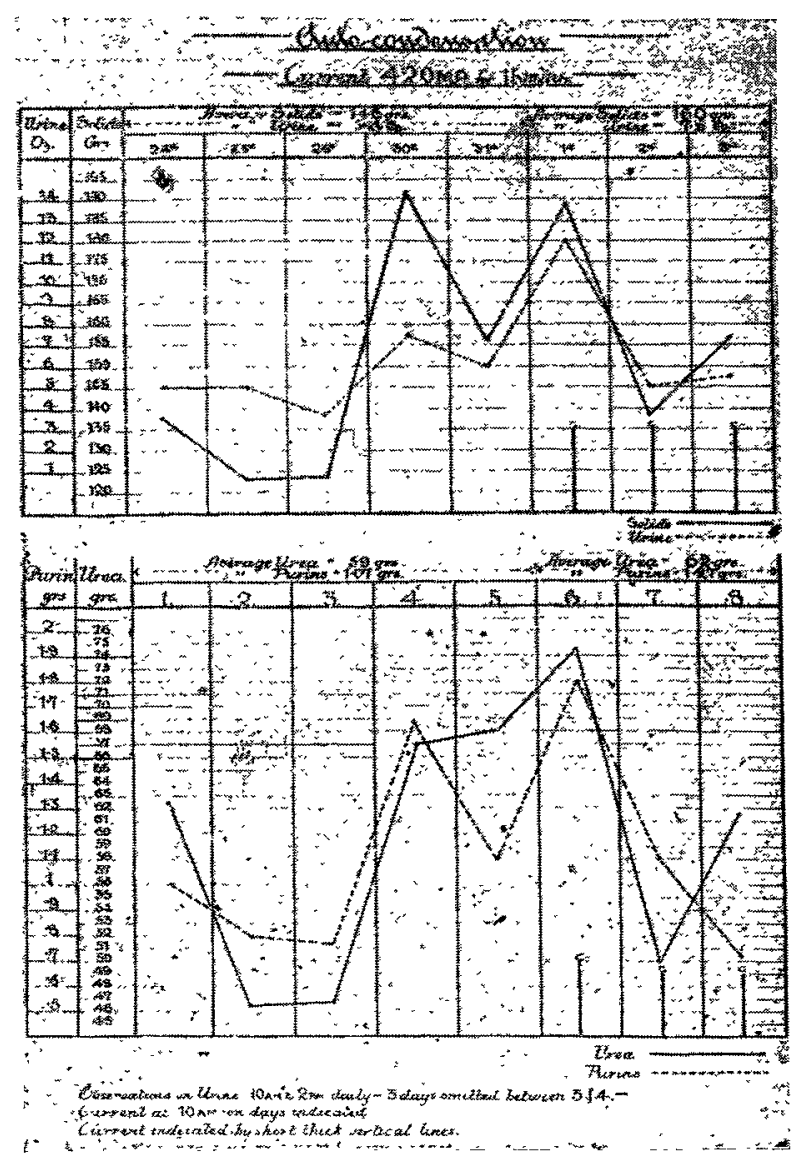

This figure is meant to show the immediats effect of the current on the urine. Five preliminary investigations are made on the urine. Five preliminary investigations are at 10 A.M. and similar measurements of the urine are made to determine the changes, if any. made on the urinar excretion of four hours, namely, from 
and habits of the patients forbid this in the interests of recovery which must be the principal result aimed at. Again this variety in the matter of diet, exercise, \&c., brings about such a daily variation in urinary excretions that one day, or even an average of several days, cannot be taken as a criterion; so that the effect of the current may be difficult to detect or measure with any degree of accuracy. It will be obvious, then, that the results of investigations in this department of the subject can only be, in a vague way, of weight. I show you examples which will illustrate these vagaries of the urinary products. (See Figs. 8 and 9 and urine tables.) You will see here that one day more or one day less on either side of the dividing line which indicates the beginning of the electric treatment may quite change an apparently important modification in the one direction into one quite in the opposite. This, however, will hardly account for a steadily maintained change in the direction of the normal for that individual under the influence of the current, where this personal factor can be obtained. (See Table X.) This table shows a steady advance towards the

TABLE X.

\begin{tabular}{|c|c|c|c|c|c|c|c|c|c|c|c|}
\hline \multirow{2}{*}{\multicolumn{3}{|c|}{ In 24 hours. }} & \multirow{2}{*}{\multicolumn{3}{|c|}{$\overbrace{}^{\text {March, 1906. }}$}} & \multirow{2}{*}{ c.* } & \multicolumn{3}{|c|}{ March, 1906.} & \multicolumn{2}{|c|}{ Average } \\
\hline & & & & & & & 17 th & 18th & 19th & Before & After \\
\hline Jrine & & & 28.5 & $26 \cdot 5$ & $21 \cdot 5$ & & $25 \cdot 0$ & $34 \cdot 5$ & $30 \cdot 0$ & $25 \cdot 5$ & $29 \cdot 8$ \\
\hline Solids & & $\ldots$ & 660 & 672 & 589 & & 707 & 834 & 660 & 640 & 733 \\
\hline Urea &,$\quad \ldots$ & & 192 & 172 & 193 & & 235 & 269 & 240 & 186 & 248 \\
\hline Purins & , $\quad \ldots$ & $\ldots$ & 5.97 & 5.83 & 5.0 & & $5 \cdot 8$ & $7 \cdot 4$ & $6 \cdot 3$ & $5 \cdot 6$ & 6.5 \\
\hline
\end{tabular}

* Current dail.

Ratio of purins to urea before $=1$ to 33 .

Ratio of purins to urea before $=1$ to 33.

\begin{tabular}{|c|c|c|c|c|c|c|}
\hline \multicolumn{3}{|c|}{ In 24 hours. } & \multirow{2}{*}{$\frac{12 / 10 / 06}{45}$} & \multirow{2}{*}{$\frac{28 / 10 / 06}{37}$} & \multirow{2}{*}{$\frac{9 / 11 / 06}{38}$} & \multirow{2}{*}{$\frac{\text { Average. }}{40}$} \\
\hline Urine (o & punces) & $\begin{array}{llll}\ldots & \ldots & \ldots\end{array}$ & & & & \\
\hline Solids & grains) & $\begin{array}{llll}\ldots & \ldots & \ldots\end{array}$ & 742 & 651 & 1003 & 798 \\
\hline Urea & ," & $\begin{array}{llll} & \cdots & \cdots & \cdots\end{array}$ & 225 & 222 & 304 & 250 \\
\hline Purins & ," & $\begin{array}{lll}\ldots & \ldots & \ldots\end{array}$ & $7 \cdot 4$ & $8 \cdot 1$ & 79 & $7 \cdot 8$ \\
\hline
\end{tabular}

Ratio of purins to urea $=1$ to 32 .

normal ; taking as this the urinary excretion of several months later, when the condition of the patient is noted as "very good," though there still existed the kidney disease as evidenced by a trace of albumin being constantly found in the urine. This is only one case but it may be none the less a valuable one. It is one that $I$ have been able to watch and to gauge the progress of with exceptional care and accuracy. In a case like this where so much benefit has followed the treatment the question arises, What has been the primary action of the current? Dr. Alexander Robertson, formerly professor of medicine, St. Mungo's College, was in charge of the case, and I was acting in conjunction with him. It was one of a very slow convalescence from uræmic convulsions. Coma had lasted for about a week; general blood-letting had been resorted to and for some days it seemed impossible for the patient to recover. Convalescence, as I have said, was very protracted and after ten weeks no appreciable progress was being made, the pulse remaining between 96 and 102. No medicine seemed to have any influence on the pulse-rate. At this stage I suggested highfrequency treatment. I said that I felt sure it would do some good; whether by influencing the general health through the kidneys or the latter through the former I could not tell. It was purely empirical knowledge only I could speak from then. Dr. Robertson agreed to the trial. We decided to stop all medicines and simply to note the condition of the patient from day to day, allowing ten days for this before beginning the electric treatment in order that we might be able to eliminate any source of error in the final result. The effect on the pulse-rate was marked. Whereas during the ten days preceding high-frequency treatment it varied between 96 and 102, it came down to 83 after the third application, practically remaining at 85 thereafter. I have no records in this case of the blood pressure at this stage because this was always taken by means of the Hill and Barnard sphygmomanometer, in which I have explained to you I have no confidence; but later, at about the time this patient's health is noted as "very good" the pulse after rest was found to be 88 and the blood pressure 218 by the RivaRocci (Martin) sphygmomanometer at 8 P.M. The blood pressure, therefore, may be taken at the period of convalescence indicated as about 180 to 200 , and the cause of the high pulse-rate at that time as the high blood pressure plus the cardiac failure, especially the latter.

Into the question of purins in the blood and their effect on the circulation and on the general health this is not the occasion to enter. I have been studying this question for many years and have made a large number of examinations of urine in connexion with the subject. Whilst Haig may be, I believe is, right in many cases in withholding a diet rich in uric acid, I have come to the conclusion that, in the case of most people, if only the diet is suited to the individual in quantity and a fair consideration given to the natural instincts in the matter of appetite, attempts should be made to improve the cardiac force and to set right the gastro-intestinal digestion, leaving the purins to take care of themselves, rather than to try to rectify faults of metabolism by washing out the purins or taking special steps to avoid their intake. I should like to draw your attention to one or two points in this connexion, however, which are illustrated in my charts and tables. In the case of nephritis referred to I found that whilst the 24 hours amount of albumin fell as the pulse-rate fell, the curve of the total purins actually rose. True, the urea was probably rising also; but if you examine Table $X$, which refers to this case, you will see that whilst the average daily amount of purins in the early part of the treatment was $5 \cdot 6$ grains, that excreted later was 6.5 grains, whilst that at the time of greatly improved health was 7.8 grains. The relation of purins to urea again became lower after the treatment and was again higher at the later stage of improved condition. Probably each man has his own purin ratio, as each one has his own urea factor; and until we can ascertain this for the individual in health it is a waste of time to argue as to the effect of the increase or decrease of the purins excreted on the general health. Look now at Table XI. Here in Oase (A) we have practically the

TABLE XI.

CASE A.

\begin{tabular}{|c|c|c|c|c|c|c|c|c|c|c|}
\hline \multirow{2}{*}{\multicolumn{2}{|c|}{ In 24 hours. }} & \multicolumn{3}{|c|}{$\overbrace{}^{\text {December. }}$} & \multirow[b]{2}{*}{ C. ${ }^{*}$} & \multicolumn{3}{|c|}{ December. } & \multicolumn{2}{|c|}{ Average } \\
\hline & & $\begin{array}{l}\text { 8th- } \\
9 \text { thh }\end{array}$ & $\begin{array}{l}9 \text { th- } \\
10 \text { th }\end{array}$ & 10th & & $24 t h$ & 25 th & $26 \mathrm{th}$ & Before & After \\
\hline Urine (ounces) & & 47 & 45 & 51 & & 30 & 38 & 42 & $47 \cdot 6$ & $36 \cdot 6$ \\
\hline Solids (grains) & $\ldots$ & 1189 & 940 & 953 & & 792 & 1045 & 924 & 1027 & 920 \\
\hline Urea $\quad, \quad \ldots$ & $\ldots$ & 470 & 450 & 408 & & 345 & 418 & 399 & 443 & 387 \\
\hline Purins,$\ldots$ & $\ldots$ & $11 \cdot 7$ & $10 \cdot 8$ & $11 \cdot 8$ & & $6 \cdot 7$ & 10 & $12 \cdot 3$ & $11 \cdot 4$ & $9 \cdot 6$ \\
\hline
\end{tabular}

* Current-10 applications 500 milliampères for 15 minutes. Ratio of purins to urea before $=1$ to 38.
$=1$ to 40.

CASE B.

\begin{tabular}{|c|c|c|c|c|c|c|c|c|c|}
\hline \multirow{2}{*}{\multicolumn{2}{|c|}{ In 24 hours. }} & \multicolumn{3}{|c|}{ November } & \multirow{2}{*}{ c."* } & \multicolumn{2}{|c|}{ December. } & \multicolumn{2}{|c|}{ Average } \\
\hline & & 23rd & 24th & $28 \mathrm{th}$ & & $26 \mathrm{th}$ & $27 \mathrm{th}$ & Before & After \\
\hline Urine & s) ... & 34 & 29 & 43 & & 47 & 35 & 35 & 41 \\
\hline Solids ( & (rains) ... & 785 & 669 & 851 & & 982 & 1001 & 768 & 991 \\
\hline Urea & $\ldots$ & - & - & 344 & & 446 & 350 & - & 398 \\
\hline Purins & $\ldots$ & - & - & $12 \cdot 1$ & & 119 & $15 \cdot 4$ & - & $13 \cdot 6$ \\
\hline
\end{tabular}

* Current-12 applications 450 milliampères for 15 minutes. Ratio of purins to urea before $=1$ to 28 . $"$ " " " " after $=1$ to 29 .

CASE C.

\begin{tabular}{|c|c|c|c|c|c|c|c|c|c|c|}
\hline \multirow{2}{*}{\multicolumn{2}{|c|}{ In 24 hours. }} & \multicolumn{3}{|c|}{ November. } & \multirow{2}{*}{ C. * } & \multicolumn{3}{|c|}{ December. } & \multicolumn{2}{|c|}{ Average } \\
\hline & & 13 th & 20 th & 22nd & & 16th & 17th & $18 \mathrm{th}$ & Before & After \\
\hline Uxine (ounces) & ... & 72 & 84 & 72 & & 66 & 66 & 60 & 76 & 64 \\
\hline Solids (grains) & ... & 1188 & 1293 & 1108 & & 1089 & 1089 & 990 & 1196 & 1056 \\
\hline Urea , , & $\ldots$ & 432 & 504 & 468 & & - & 462 & 420 & 468 & 441 \\
\hline Purins ", & ... & $17 \cdot 7$ & 18 & $16 \cdot 7$ & & $15 \cdot 8$ & $16 \cdot 3$ & $13 \cdot 9$ & $17 \cdot 4$ & $15 \cdot 3$ \\
\hline
\end{tabular}

* Current-six applications.

Ratio of purins to urea before $=1$ to 27 
same ratio of purins to urea at the close as at the beginning of the treatment; although the treatment immediately improved the general health. The same may be said of the case referred to in Fig. 9, where the ratio is 1 in 55 before and 1 in 53 after treatment; and yet my notes say

FIG. 9.

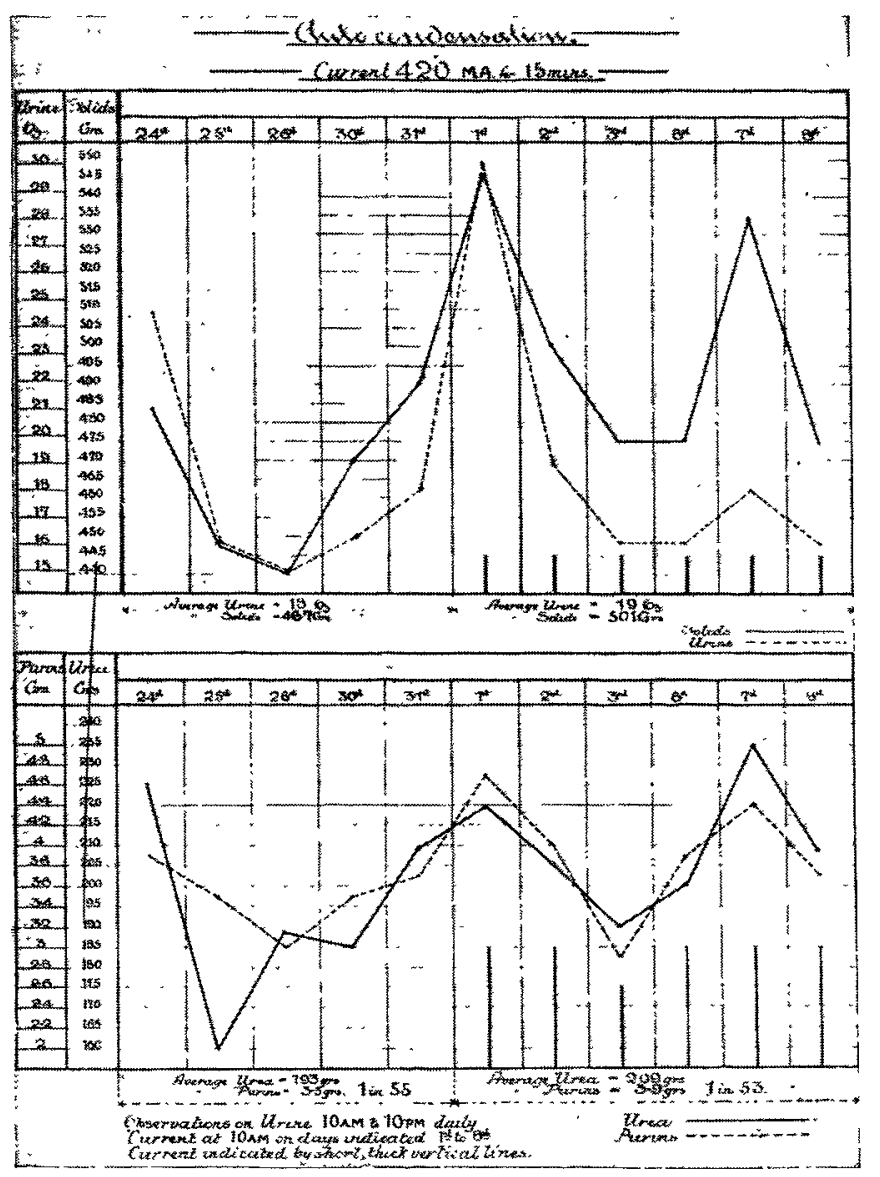

Here measurements are made of the total urine from 10 A.M. till 10 P.M. for five days before and for six days after the beginning of the electric applications, these being daily at 10 A.M.
Retino-oerebral mechanism.-I have considered the physiological effects of high-frequency currents from the points of view of the cardio-vascular, thermo-genetic, gastrointestinal, and renal systems. Can any of these, or all of them put together, explain the various signs and symptoms we know to expect from this treatment? I am sure they cannot. They give no explanation of certain sensations remarked upon by patients when undergoing auto.condensation treatment. One patient will say that the after-effect is a sense of "comfortable weariness in contrast to fatigue or faintness." Another I have heard remark : "I feel for an hour or two after a restful weariness which is just lovely." One lady, after the vacuum electrode from the high-frequency solenoid had been applied to the supra-orbital region for neuralgia, remarked to me the following day: "I don't know what you have done to me or how you have done it, but since yesterday a load has been lifted from my mind and all my cares are gone." For years this lady seemed to have a weight of care on her and there had I knew been much cause for this. Yet at her subsequent visits and until I last saw her she declared that her burden of mental distress had not returned. Unfortunately, this is an exceptional case ; but it will serve as an illustration of the point I wish to enforce-viz., that some action on the central nervous system takes place under the therapeutic use of these currents. How is this effect to be seen or measured? We cannot see what is going on in the brain, but we may see and measure what is going on in the retina, which, after all, is a prolongation of the brain. What is called the "after-image" may by the measurements of its duration give us some indication of the condition of the retino-cerebral mechanism. Physiologists whose works I had consulted declare that the duration of this afterimage is proportional to the cerebral fatigue present. Haig maintains that the undue prolongation of the positive afterimage is due to a state of collæmia of the capillaries of the retina, and this condition, according to him, is caused by excessive uric acid in the blood, which again is a cause of cerebral malnutrition. I tried to measure the duration of the positive after-image on myself but gave this up for several reasons. The exposure of the eye to a strong light for several seconds was uncomfortable, if not mischievous; besides, it seemed impossible for ine to fix a moment of time in the course of its disappearance as a measure of its duration, and further it continually eluded me in my endeavour to keep it stationary. I then decided to measure the duration of the negative after-image as an index of the cerebral fatigue. I soon, however, had reason to doubt regarding this case at the close of the treatment: "General condition improved, no rheumatism, no restlessness of legs now." The rheumatic condition must be more than a mere matter of purins. Look again at Cases (B) and (C) in Table XI. and you will find very little change in the purin-urea ratio in either, and yet, in the former at least, the condition improved vastly after the electric treatment. In this Case (B), one of obesity, the urea and the purins have both increased under the treat. ment. I have pointed out, however, that this is not an invariable result. Indeed, looking at Case (A) you will there see that where a like benefit had followed exactly the opposite had occurred.

I have left myself very little time to speak of the Joulie urinary coefficients. Let me just say that by this is meant the actual amount of phosphates of the urina sanguinis per litre per cent. specific gravity, divided by the total acidity per litre per cent. specific gravity. The normal figure for the phosphates, reckoned as $\mathrm{P}_{2} \mathrm{O}_{5}$, is $11 \cdot 17$, that of the acidity $4 \cdot 55$, the ratio being thus $2 \cdot 45$. From the variation in these figures Joulie draws important conclusions regarding the metabolic processes and the indications for treatment. Whether electric treatment by high-frequency currents would modify these figures I have not yet settled in my own mind, though I have made numerous experiments in this direction. I may return to this subject on a future occasion.
FIG. 10.

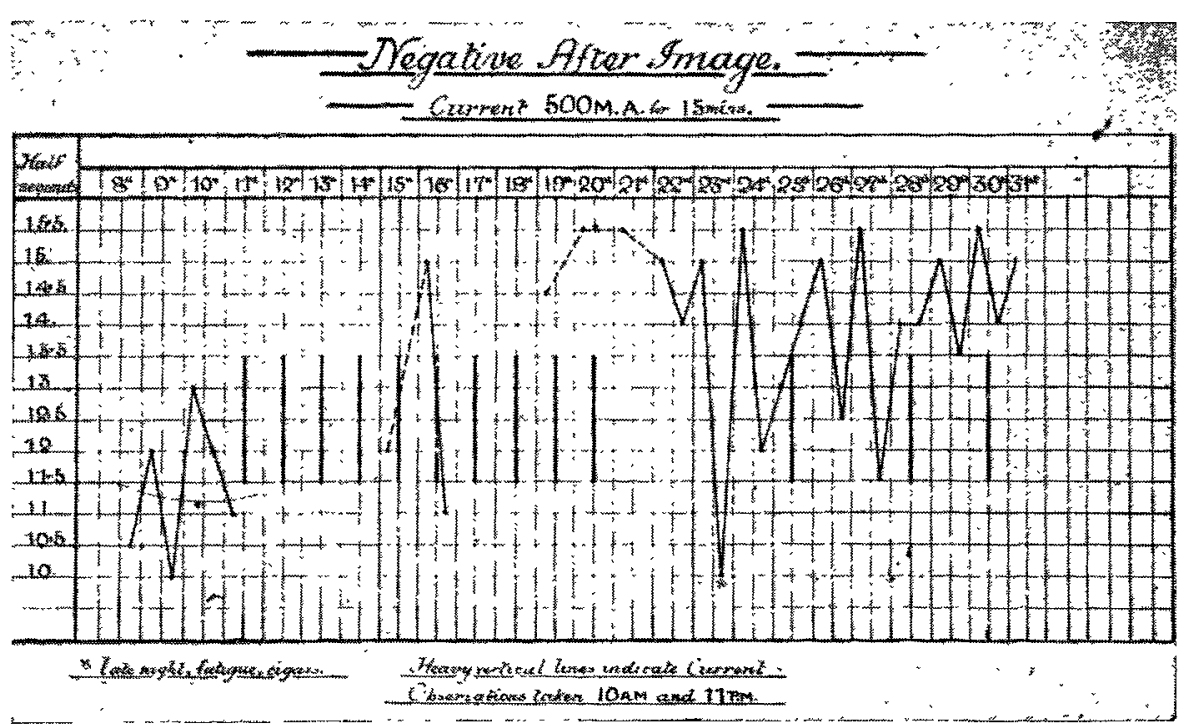

whether this, the duration, was directly proportional to the cerebral fatigue, and I began to suspect that it was rather inversely proportional to this, since the fresher $I$ was the longer did the after-image remain. I also noticed that the duration was longer in the morning than at night and longer with the young and the strong than with myself. On satisfying myself as to these points I consulted various other authorities and discovered that the opinions of physiologists were about equally divided on the subject of the after-image 
as an indicator of the retino-cerebral condition, some maintaining that its duration was directly proportional to the fatigue, others that it was inversely so.

Let me here explain, for the benefit of those of you who may not have studied this subject, the nature of the negative after-image and the means for accurately measuring its duration.

(Explanation given and the means of observation shown.)My experience has led me to the following conclusions: 1. That the duration of the negative after-image is different in different individuals. 2. That in the same individual it differs according to the state of the health, being longer when the person is well and fresh than when ill and fatigued; according to the time of day, being, at least in my own case, longest just after breakfast and shortest at bedtime. I could, indeed, tell with a fair amount of certainty how fit or unfit I was going to be during the day by taking $m y$ negative after-image in the morning, and $I$ could fairly correctly gauge what it was going to be when I had finished my day's work. When, by reason of temporary good spirits giving me the feeling of being particularly fit, I expected to find it high in spite of a specially hard day's work, I discovered that this was not the case, the duration being less owing to the previous fatigue. I can with a metronome beating balf seconds reckon the duration in my own case to a quarter of a second. A considerable amount of experience is necessary, however, to be able to measure with sufficient scientific accuracy the duration of one's own afterimage. Accordingly I have not been very successful with other people ; but I recommend the matter to your consideration as interesting and as of scientific value. The examination must take place as near as possible at the same hour, the light must be the same, the distance of the light from the image the same, and the distance of the eye from the object and the image also the same, as well as must the metronome beat at exactly the same rate and for the same number of half seconds before the eye is turned towards the white paper. The image generally appears at once, but with some people there is a delay of a few half seconds before its appearance. With most the image returns two or three times but this is not reckoned in the measurement. Unless the eye be kept fixed on one spot the record is spoiled. Accordingly I have, as you see, fixed a pin in the centre of each paper to keep the eye fixed on, since if it wanders from the spot it was originally fixed on the image at once disappears. Fig. 10 is a good example of the negative after-image record in a case where the benefit derived from the current was most marked. You will observe that the average for the six times noted before the beginning of the treatment is slightly under $11 \cdot 5$, that for the time succeeding the treatment slightly over 14 . Note also the effect of fatigue on one occasion and also that, when the duration of the image is ceasing to be so favourable after the treatment had stopped, one application of the current has raised the night record to a higher level than that of the morning of the same day.

Questions worthy of consideration as to future investigations.-1. Do the physiological results differ where the amount of the current is the same but the initial voltages differ? 2. Can any changes in the retinal vessels be observed? 3. What influence may the time of application have with relation to meals? 4 . What are the effects of varying doses and duration of application under exactly the same conditions of the patient? 5 . What might be the effect of high-frequency currents on the growth or virulence of bacteria, with special reference to those found in disordered conditions of the intestinal canal? 6. What, if any, influence have these currents on the urina sanguinis with relation to the Joulie ratios? Finally, let me again advise the appointment of a scientific investigation committee.

Glasgow.

WeLsh Medrcal Dinner.-The fourth annual Welsh medical dinner was held in London on May 31st, under the presidency of Sir Isambard Owen. There was a good attendance and amongst those present were Sir R. Douglas Powell (President of the Royal College of Physicians of London) and Mr. Henry Morris (President of the Royal College of Surgeons of England). Sir Isambard Owen, in the course of an interesting speech, alluded to the fact that the University of Wales was securing a supplemental charter to empower it to confer degrees in medicine and surgery.

\section{VARIATIONS IN THE AGE-INCIDENCE OF MORTALITY FROM CERTAIN DISEASES.}

\author{
By SIR SHIRLEY F. MURPHY,
}

MEDICAL OFFICER OF HEALTH $Q F$ THE ADMINISTRATIVE COUNTY OF LONDON.

AT the request of your secretaries I am proposing to submit for your consideration a series of diagrams showing change in the age-incidence of mortality from certain diseases. The subject has been from time to time discussed in reports I have presented to the London County Council but although it is not entirely new I hope the diagrams will be found to be of sufficient interest to the meeting to justify me in occupying a part of the evening in their exhibition.

I wish, in the first instance, to state how these diagrams have been constructed, in order that they may be perfectly intelligible. The method of construction is the same in each instance. The mean death-rate at each age in the whole period under consideration is taken as a standard, and the death-rate at each age in each quinquennial or decennial period is stated as a percentage above or below the mean of the whole period. Thus the death-rates at the several ages over the whole period are represented by a straight line, and the excess or defect of the death-rates at these ages in each quinquennial or decennial period forms a curved line above or below the mean. It is obvious that by this method any deviation from a straight line represents variation in the age-incidence of mortality.

The first diagram (Fig. 1) which I will ask you to look at is based upon the deaths in London from diphtheria and croup from the period 1859 to 1905 . The first period represented by a curved line relates to the years 1859 and 1860, while all other

FIG. 1.

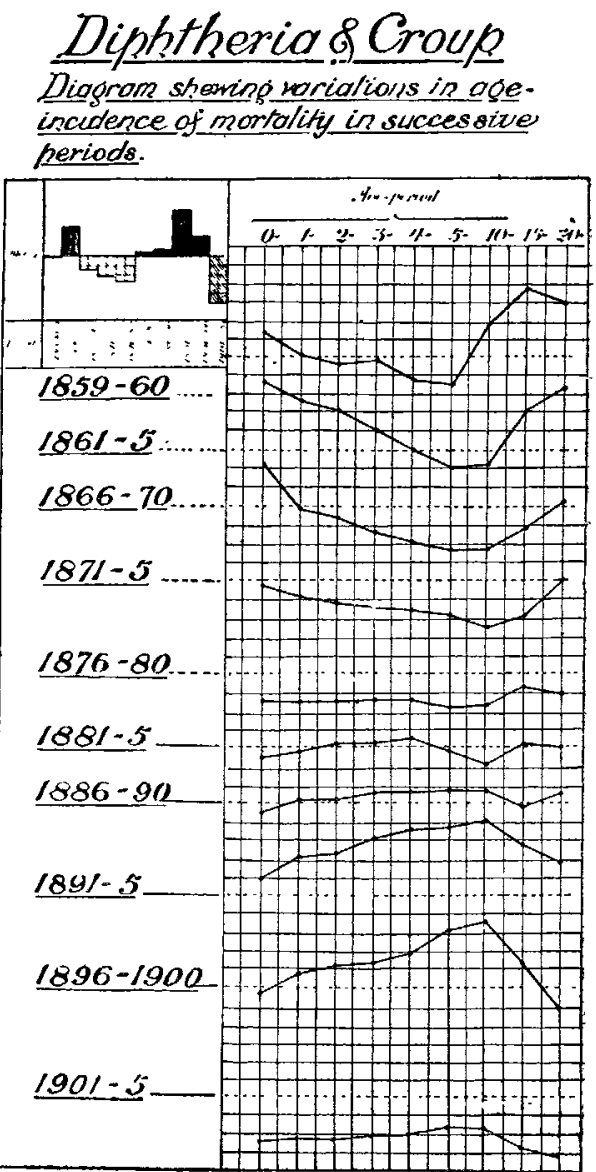

lines relate to quinquennial periods. The curves of 1859-60 and 1861-65 closely resemble each other. The line is bent with the convexity downwards, the ages 4,5 to 10 and 10 to 15 being in the second period the three lowest points in the curve. The period 1859-65 was one of epidemic prevalence. The next three quinquennial periods are periods of decline of prevalence, but it will be seen that this decline has been obtained not so much by decline at the ages $I$ have mentioned as by decline at ages below and above those ages, so that the line representing the period 1876-80

I $A$ paper read before the Epidemiological Society on March 5 th, 